\title{
Are There Edenic Grounds of Perceptual Intentionality?
}

\section{Citation}

Siegel, Susanna C. 2013. Are there Edenic grounds of perceptual intentionality? Analysis 73 (2):329-344.

\section{Permanent link}

http://nrs.harvard.edu/urn-3:HUL.InstRepos:9938751

\section{Terms of Use}

This article was downloaded from Harvard University's DASH repository, and is made available under the terms and conditions applicable to Open Access Policy Articles, as set forth at http:// nrs.harvard.edu/urn-3:HUL.InstRepos:dash.current.terms-of-use\#OAP

\section{Share Your Story}

The Harvard community has made this article openly available.

Please share how this access benefits you. Submit a story.

\section{Accessibility}


To appear in Analysis Reviews in a symposium on David Chalmers's The Contents of Consciousness, Oxford 2010. Page numbers refer to this volume.

\section{Are there Edenic grounds of perceptual intentionality?*}

The essays in "The Character of Consciousness" sketch a comprehensive theory of intentionality, aimed at explaining how linguistic items and mental states get their contents. The framework of two-dimensional semantics includes the thesis that sentences, beliefs, and experiences each have two sets of contents, and an explanation of the underlying dispositions that ground those contents. The contents take the form of two intensions. Primary intensions correspond to the cognitive significance of the utterance, belief, or experience, while secondary intensions correspond to environmental aspects of their meaning.

In the case of experience, the two-dimensional framework is supplemented with a story about the role of phenomenal character in grounding the contents of experience. Every phenomenal aspect of experience finds expression in the framework of representation, in the form of a satisfaction condition. Experiences of objects have one type of satisfaction condition, experiences of properties have another, and when combined, they produce conditions on veridicality of experiences - not just visual experiences, but experiences in all sensory modalities, including bodily sensations. The phenomenal character of experiences is thus deeply connected to representation. "Intentional content appears to be part of phenomenology: part of the essential nature of phenomenology is that it is directed outward at a world (371)." In fact, according to Chalmers, phenomenology is systematically connected to intentional content twice over. And here Chalmers's discussion of the phenomenal grounds of representation contains two independently motivated ideas.

The first idea is that phenomenal character, all by itself, determines a unique profile of properties that the world would have to instantiate, in order for it to be the way it appears. For any experience, we can ask: how would the world have to be, in order to be precisely the way it is

*

* For discussion thanks to David Bennett, Ned Block, Alex Byrne, David Chalmers, Eric Mandelbaum, Farid Masrour, Nico Silins, Maja Spener, Daniel Stoljar, and Scott Sturgeon. 
experienced? The idea that this question always has an answer is the conceit of Eden, a mythical place that embodies the perfect match between things in the world and our experiences of them. In Eden, things mirror how they appear, by having exactly the properties that they appear to have.

The mythical construct of Eden vividly illustrates a set of constraints on veridicality placed by phenomenal character. Eden shows us what the world would be like, if the constraints placed by phenomenal character were fully met. The constraints are that things have perfect properties, which by definition mirror phenomenal character. Chalmers argues that our world is not Eden, because (for the most part) perfect properties are not instantiated. But the fact that the constraints are not met here does not stop our experiences from having Edenic contents, which are a form of Russellian content, composed of objects and perfect properties. He proposes (somewhat speculatively, 454) that our relation to Edenic contents constitute the fundamental nature of phenomenal character.

The second idea is that the phenomenal character of experiences does not determine a unique profile of properties that the world would have to instantiate, in order for it to be the way it appears. Instead, the phenomenal character of an experience determines a satisfaction condition that can be met by a wide range of properties. The satisfaction condition includes causal constraints and structural constraints. For instance, a phenomenally red experience imposes the constraint that to be veridical, experience has to be caused by the property that normally causes phenomenally red experiences, and that stands in structural relations of color similarities - and that could be any property that is properly embedded in the environment. Satisfaction conditions of this sort make up the Fregean contents of experience. Fregean contents co-vary with phenomenal character, though different properties satisfy those contents in different worlds.

These two ideas about the relationship between phenomenal character and representation can seem directly at odds. According to the first idea, each experience determines a unique profile of properties such that the experience is veridical, only if those properties are instantiated, whereas according to the second idea, each experience determines a veridicality condition that can be met by different properties in different worlds. Chalmers thinks the two ideas peacefully co-exist, by virtue of a tacit switch between standards of veridicality. When we focus on the conditions that mirror phenomenal character, we hold experience to perfect standards. At other times, we relax the standards for veridicality, and count experiences as veridical, even when things as they are don't mirror phenomenal character. The relaxed standards of veridicality are supposed to be the default, whereas perfect standards of veridicality exaggerate the need for veridicality conditions 
to match phenomenal character. We can take a perspective on our experiences (either as theorists or as introspectors) in which we hold it to perfect standards. But in taking this perspective, we depart from our ordinary standards of veridicality.

The two phenomenal contents differ starkly. On the one hand, Edenic contents both mirror phenomenal character and constitute its fundamental nature. Our experiential relation to Edenic contents is a relation of acquaintance to perfect properties that rules out a priori certain forms of ignorance about those properties (430). We're acquainted with their instances in Eden, and with uninstantiated universals in fallen worlds. ${ }^{1}$ Given the constitutive role of Edenic contents in phenomenal character, acquaintance with perfect properties helps explain how we can be acquainted with our own experiences as well. In particular, experiences of perfect properties help ground pure phenomenal concepts, which play a central role for Chalmers in his theory of introspection and his response to anti-dualist attempts to explain away the explanatory gap. By contrast, the Fregean contents of experience merely co-vary with phenomenal character without mirroring it, and without constituting its basic nature. They embody an epistemically much weaker relation to imperfect properties than perceptual acquaintance, and they do not explain the introspective acquaintance Chalmers finds one level up - acquaintance with experiences.

The most important difference between the two phenomenal contents regards our first-person phenomenal perspective on the external world in perception. The Edenic contents best reflect that perspective, whereas the Fregean contents reflect it imperfectly at best, or at worst, not at all. This difference could be summarized in Chalmers's remark that "Presentational phenomenology does not wear its Fregean content on its sleeve" (435). Phenomenal contents are not monolithic in how they reflect the first-person perspective we have on the external world in perception.

I'll use "presentational phenomenology" for phenomenal character that goes with our firstperson perspective on the external world in perception. ${ }^{2}$ In Chalmers's framework,

1

? Hellie (this issue) discusses this distinction, and Pautz (2011) defends the view in detail.

2

? Chalmers glosses "presentational phenomenology" like this (371): "the way that [perceptual experience] seems to directly and immediately present certain objects and properties in the world" 
presentational phenomenology is the Edenic content relation. The notion need not be defined in terms of his framework, but it is motivated by his idea that the contents that reflect the firstperson perspective differ from those that reflect ordinary veridicality conditions. Absent Chalmers's distinction between the two phenomenal contents, presentational phenomenology would be phenomenology, simpliciter.

Once we zero in on presentational phenomenology, we can ask what psychological and rational roles it plays in perception and perceptual belief. In perception, Chalmers claims that Edenic contents ground epistemically rigid concepts, which rule out various kinds of ignorance about perfect properties (265). I argue in section 1 that even in Eden, a kind of ignorance could arise that Chalmers claims to rule out. In section 2, I make the case that given Chalmers's commitments, Fregean contents must do all the heavy lifting in perceptual belief. Those contents explain which perceptual beliefs we form, and how they are justified. I argue that the resulting epistemology of perceptual belief rests on an implausible psychological thesis: we systematically fail to take at face-value our first-person perspective on the external world. Chalmers's thesis that there are two phenomenal contents has the implausible consequence that the contents that determine what we normally believe in perception differ from those that most immediately reflect our first-person perspective. This consequence is a reason to doubt that phenomenal contents divide in the way Chalmers proposes.

\section{Are there Frege cases in Eden?}

It is natural to think that acquaintance with a property would rule out ignorance about its intrinsic nature. In Chalmers's framework, one version of this idea is that acquaintance with a property grounds a concept of that property that is epistemically rigid, where this means that its primary intension picks out the same referent in every epistemically possible scenario (265). ${ }^{3}$ If $a$ and $b$ are epistemically rigid, then $a=b$ is a priori. Epistemic rigidity yields an idealized analog of acquaintance: when $a$ and $b$ are epistemically rigid concepts of the same property, ideal a priori

3

? Chalmers holds that epistemically rigid concepts typically also pick out the same property in every metaphysical possible world (they're subjunctively rigid, 265). 
reflection will reveal that they are the same property (from now on take the idealization as implicit). In what follows, I will take acquaintance with a property to be understood in this way.

Chalmers apparently holds that we are acquainted with perfect properties, in the sense operative here. He says that experiences of perfect properties are associated with the same primary and secondary intensions (404). And in his theory of introspection and his interpretation of the explanatory gap, he relies on the idea some of our concepts of our own experiences - the pure phenomenal concepts - are epistemically rigid. Chalmers seems committed to the existence of concepts of perfect properties (call these "Edenic concepts") that are epistemically rigid. Given that experiences are supposed to consist in acquaintance with Edenic properties, if experiences do not ground epistemically rigid Edenic concepts, then it is hard to see how there could be epistemically rigid phenomenal concepts.

All subjects can have Edenic concepts (if any can), given the assumption that experiences consist in a relation to (sometimes uninstantiated) perfect properties. If our experiences of perfect properties ground Edenic concepts that are epistemically rigid, then there are no Frege cases involving perfect properties. In such a Frege case, a subject experiences the same property on two occasions, but for all her experience or a priori reflection tells her, it may not be the same property both times. If we are acquainted with flatness twice over, once visually and again through touch, then we can know a priori that the same property is experienced both times.

Before turning to the apparent examples of Frege cases in Eden, it is useful to distinguish between different ways to endorse an experience.

Consider Edenic Mary, who has never seen colors before. Suppose Mary knows that she is about to see either red or green, and that she will thus have either a phenomenally red or a phenomenally green experience. ${ }^{4}$ She is shown a red swatch, and has a phenomenally red experience. Since she doesn't know that the swatch is red, she does not form the belief that would be most natural to express by saying "The swatch is red". But she believes that the swatch has the color property that it appears to have. If we distinguish between the standing concept of red and a demonstrative concept of red, we can describe Edenic Mary's situation by saying that

Stalnaker 2008 discusses a case like this. 
when she endorses her experience, she uses a demonstrative concept of redness (that color), but does not apply her standing concept of redness.

Edenic Mary illustrates the difference between endorsing an experience while conceptualizing it using a standing concept, and endorsing it without conceptualizing it in that way. This distinction figures in the Frege cases that I argue could arise in Eden.

\section{Intramodal Frege cases}

Imagine you are bicycling on a road. You can feel the difference between going uphill, going downhill, and traversing a flat surface. Feeling the slope of the road through pedaling is a kind of haptic tactile perception, akin to feeling the consistency of soup by stirring it with a spoon.

When you feel the slope of the road through pedaling, you feel it in part by feeling resistance when you pedal. There is little resistance going downhill, a lot going uphill, and a medium amount on flat roads. Although felt resistance is only one aspect of tactile experiences of the road, it is a partly constitutive of it. Absent any feeling of resistance, you could not feel the road through pedaling at all (cf Smith's (2002) discussion of the Anstoss). You feel the flatness of the road, by feeling its resistance. You can't factor out the experience of flatness from the experience of the road's resistance to your pedaling. The tactile experience of flatness cannot be isolated from the feeling of resistance, in the way that a cyclist could arguably isolate the flatnessexperience from experience of their energy level, or from other factors that always accompany tactile spatial experiences.

Felt resistance to pedaling can be caused by many factors besides the slope of the hill, both mechanical (muddy surface, dirty chain), and energetic (more resistance is felt when the cyclist has a relatively lower energy level, and less resistance with a higher energy level - even on flat roads.) There is thus a range of degrees of resistance one could feel when pedaling on a flat surface. In this range, is there a unique degree of resistance that could figure in veridical tactile experiences of flatness? If not, then given the constitutive role of feelings of resistance in tactile experience, flatness could be mirrored in Eden in more than one way. The multiplicity in degrees of felt resistance won't preclude mirroring between the road and the way phenomenal character presents it.

We should expect to find multiple tactile experiences that mirror flatness. One's energy is always 
at some level. Variations in it can affect degrees of felt resistance, and the variations can be slight. Felt resistance can change, even when vestibular (and visual) cues that indicate orientation to the ground stay the same. Given these micro-changes in felt resistance, it seems arbitrary to select a unique degree of resistance that reveals perfect flatness. Perhaps at the extremes, utter exhaustion could create the illusion that the road slopes up, and high energy the illusion that it slopes down. But in the large middle range, there is not plausibly a unique point at which perfect flatness is revealed.

A potential gustatory analog is the taste of alcohol. You may taste the alcohol in beer, rumsoaked cake, and wine sauce on fish, but it is not exactly the same alcoholic flavor each time. You cannot completely isolate the flavor of alcohol from its surrounding flavors. (And you need not be experiencing the 'high-level' property of being alcohol to taste the alcohol, and more than tasting the sweetness of sugar involves experiencing the high-level property of being sugar.)

These examples suggest a first challenge to the Edenic picture. Edenic content is supposed to be Russellian, so that any phenomenal difference is a difference in which perfect properties are experienced. But if there are phenomenally different experiences with which one can experience flatness (or alcohol), then such contents (Edenic or otherwise) cannot be Russellian. I'll focus on flatness.

Even if there are multiple phenomenally different ways to experience perfect flatness, that does not yet show that there are Frege cases in Eden. It could be that for any pair of phenomenally distinct experiences in which one experiences perfect flatness, it is always knowable a priori that the same property is experienced both times. If so, then whenever one experiences perfect flatness, one is acquainted with it.

Let's stipulate that someone believes a road is flat if she believes it is flat, using a standing concept of flatness. I argue below that a subject who is competent with the concept flat, often applying it correctly and confidently to roads she experiences as flat, might find herself in what I'll call a cyclist situation (since my example involves bicycling): she (i) experiences a road as flat, (ii) knows by introspection exactly how the road appears to her with respect to slope, and (iii) is rationally unsure whether the road is flat, even though she endorses her experience (for instance by using a demonstrative concept that picks out the slope of the road).

If cyclist situations could happen, then Frege cases are near. Call the subject's putative experience of flatness in the cyclist situation ' $b$ ', and let ' $a$ ' be any experience of flatness when 
she is disposed to apply her standing concept to the property she experiences. For this subject, 'a $=\mathrm{b}^{\prime}$ will not be a priori.

Here is an example of the cyclist situation. Suppose you are riding on a flat road, feel resistance to degree $\mathrm{N}$, and are rationally disposed to judge on that basis that the road is flat. Since so far, the experience could be a straightforward case of experiencing flatness, call this experience ' $a$ ', and let's say it occurs at time $\mathrm{t} 1$.

Now for the putative experience ' $b$ '. At time $t 2$, your legs feel tired, and the felt resistance is degree $\mathrm{N}+$, phenomenally not much different from felt resistance degree N. Memory tells you that it just got harder to pedal. You're sure that you are more tired than at $\mathrm{t}$, but not sure whether increased resistance is due entirely to decreased energy level.

Could your experience of the road at this point be an experience of flatness? Of course your experience could be caused in a normal way by flatness, but could it be an experience that presents the road as flat?

To see why it could, consider the different experiences a subject in this situation could in principle have. The options are these:

Slope illusion: At $\mathrm{t} 2$, the tired cyclist experiences the road as sloping upward.

Indeterminacy: At $\mathrm{t} 2$, the tired cyclist experiences the road as having a slope that is nearly flat somewhere in the range from flat to slightly inclined.

Flatness: At $\mathrm{t} 2$, the tired cyclist experiences the road as flat.

The key point favoring the flatness possibility is that competence with the standing-flatness concept does not plausibly require being rationally disposed to apply it in response to every experience representing perfect flatness - assuming any non-experiential factors relevant to rationally applying the concept are in place. (From now on, I'll assume that the non-experiential factors relevant to justification are the same in the isolated and successive conditions, and leave this assumption implicit). Expert cyclists would respond to any such experience by applying the standing flatness-concept. But novice cyclists may not always rationally be able to distinguish between increases in felt resistance that are due to drops in energy level, and increases due to slight changes in the grade of the hill (undetected by vestibular or visual experience). The rational response for them in a cyclist situation, given that they endorse their experience, is to suspend judgment on whether the road is flat. 
To rule out the flatness option, Chalmers would have to hold that every non-illusory experience of flatness "resolves" from having less determinate to more determinate content upon the subject applying the standing concept to it. But it is implausible to suppose that the transition from partial to full expertise would have to change experience in this way. Not even proponents of the idea that changes in expertise can change the contents of experience (such as Siegel 2010) hold that every such change changes the contents of experience. Some learning is phenomenologically stable: the experience stays the same, and one simply learns that a standing concept is appropriately applied in response. Given the wide range of experiences of flatness, due to the wide range of degrees of resistance, there will be numerous occasions on which subjects experience flatness by feeling a novel degree of resistance.

An opponent might object that it is conceptually impossible to possess a standing flatnessconcept, yet lack the rational disposition to apply it in response to an experience of perfect flatness. On this view, a subject who is rationally disposed to suspend judgment on flatness in response to their experience cannot be experiencing perfect flatness. This view assumes that the minimal experiential bearers of phenomenal character always align exactly with the minimal experiential bases that determine what (if anything) is rational to believe on the basis of the experience. But those two things do not always align.

For instance, suppose you simply started out feeling resistance $\mathrm{N}+$, without coming to it via feeling resistance N. Call this the isolated condition, and suppose that it is rational for you to judge on the basis of your tactile experience including $\mathrm{N}+$ that the road is flat. In the contrasting successive condition, you first feel resistance $\mathrm{N}$ and then resistance $\mathrm{N}+$. If the rational responses to the $\mathrm{N}+$ experiences have to be the same in both conditions, then the rational responses are symmetrical.

Symmetry: If it is rational to judge that the road is flat on the basis of the $\mathrm{N}+$ experience in the isolated condition, then it could not be rational to suspend judgment on the basis of felt resistance $\mathrm{N}+$ in the successive condition.

One might support the symmetry claim as follows. By hypothesis, feeling resistance $\mathrm{N}+$ is phenomenally the same in both conditions. If the experiences are phenomenally the same, they must present the same property. So if the presentation of that property is the main experiential factor determining which doxastic attitude is rational to take, then we should expect the same doxastic attitudes to be rational each time. 
In reply, there is reason to reject the symmetry claim. In the successive condition, $\mathrm{N}+$ is part of an extended tactile experience that differs phenomenally from the tactile $\mathrm{N}+$ experience in the isolated condition. Holding constant any non-experiential factors that may matter for justification, the doxastic attitude that is rational to adopt in the successive condition is plausibly determined by the extended experience, not by the $\mathrm{N}+$ portion of it on its own. The $\mathrm{N}+$ experiences are the same in both conditions, yet rational responses to the experiences differ, because the experiences that determine those responses differ in each case. In the successive condition, the $\mathrm{N}+$ experience taken on its own is not available as an experiential basis for any rational judgment about slope of the road. It would be irrational to ignore the other portion of the extended experience when forming an attitude on the basis of tactile experience about whether the road is flat. Here the minimal experiential bearers of phenomenal character do not align exactly with the minimal experiential bases that determinate what (if anything) is rational to believe on the basis of the experience.

My defense of Frege cases involving flatness in Eden rests on two central theses. First, there is no phenomenally unique experience of flatness. Second, subjects could rationally suspend judgment on whether a road is flat, in response to an experience of flatness that they endorse. My case for the second thesis relies on the idea that the temporally surrounding experiences can influence how it may be rational to respond to such an experience of flatness, even holding constant non-experiential factors relevant to justification.

The putative Frege case here involves two experiences in the same sensory modality. I now turn to Frege cases where the same property is experienced in different sensory modalities.

\section{Intermodal Frege cases}

Chalmers's idea that there are no Frege cases involving perfect properties dovetails with the thesis that experiences of the same spatial property in different sensory modalities share a phenomenological commonality. Often when we feel and see something flat, we know that the property we're seeing is the same as the property we're feeling. Chalmers suggests that this knowledge comes from phenomenology alone:

Phenomenologically, it seems that when an object looks flat and when it feels flat, it looks and feels to have the same property (flatness). This commonality seems to hold in virtue of an internal relationship between the phenomenology of visual and tactile experiences (395). 
The cyclist case could be adjusted to create an intermodal Frege cases which raises additional challenges to the Edenic picture. Back in Eden on your bicycle, it is $\mathrm{t} 2$ in the successive condition. While pedaling you feel resistance N+. Simultaneously you see the road, and it looks just the way it looked at $\mathrm{t} 1$ : flat. At $\mathrm{t} 2$, going by vision alone, you'd endorse your visual experience and apply the standing flatness concept to the road. At the same time (t2), going by tactile perception alone, you'd suspend judgment on whether it is flat, just as in the intramodal case.

One might think intermodal cases would be avoided if Edenic spatial experiences were always amodal, rather than being experiences within a sensory modality. If there are only ever amodal experiences of spatial properties, rather than distinctly visual and distinctly tactile experiences, then the phenomenal differences between sensory modalities would not provide a foothold for Frege cases. But this way of avoiding intermodal Frege cases seems at best to be a way to move the bump in the carpet somewhere else. Visual flatness has a visual aspect, tactile flatness has a tactile aspect. On the amodal option, Chalmers would need to account for this phenomenal difference, consistently with the idea that all differences in phenomenal character are reflected in content relations ("part of the essential nature of phenomenology is that it is directed outward at a world"). Given that we can see flatness, what world-directed visual aspect of this experience is left over, once flatness is experienced amodally? There don't seem to be enough world-related properties to go around.

A different attempt to prevent intermodal Frege cases would countenance two perfect flatness properties, one each for visual and tactile experiences of flatness. But if these properties are phenomenally different, then it is hard to see where the "internal unity" Chalmers describes enters in. He might reply that even if there is no internal unity at the level of experience, ideal reflection shows that it is epistemically impossible for flatness $_{\text {touch }} \neq$ flatness $_{\text {vision }}$ (where these are the two perfect flatness properties). But why is the best explanation for putative intermodal cyclist-based Frege cases that the subjects fail to ideally reflect on their experiences, rather than that they need more practice applying spatial concepts in the full range of circumstances?

A last type of potential Frege case involves number. Consider creatures who can add taps to taps, and flashes to flashes, but not taps to flashes. If they cannot perform numerical operations across sensory modalities, it seems natural to suppose that they also cannot know on the basis of experience or a priori reflection whether the number of taps $=$ the number of flashes, even when the number is six both times. Why does this ignorance preclude the number six from mirroring any of these experiences of quantity? If mirroring isn't precluded, then it seems that creatures in 
Eden with these limited intermodal capacities would be subject to Frege cases involving number. In fact, it seems that such Frege cases could arise in us, even though we can add across modalities. Suppose you hear six taps, grouped into three pairs, and then see six flashes in a row (thanks to Ned Block for the example). We might not know just on this basis whether it was the same number of flashes and taps each time.

One might reply that Frege cases here don't arise because the number six is not represented in these experiences under the mode of presentation six, but rather under the mode of presentation the number offlashes [/taps]. That reply raises the question of how either of the experiences would be phenomenally different, if six were represented under the mode of presentation sixness. Since in Eden, flashes mirror our experience of them, how many flashes are there, if their number is not represented under the mode of presentation six? (This is a version of the speckled hen challenge.) Pending answers to these questions, these cases suggest that we are not acquainted with the properties that mirror our experience of them.

I turn next to Chalmers's account of the role of presentational phenomenology in perceptual belief.

\section{Chalmers's psychology of perceptual belief}

Although Edenic contents and Fregean contents are motivated independently, Chalmers thinks there is an explanatory connection between them which centers on matching, a relation between perfect and imperfect properties. Consider redness. In a world w, F has to match perfect redness as well as possible, in order to be imperfect redness in w. Two aspects of matching are being a normal cause of phenomenal redness, and standing in certain structural relations to the normal cause of other color experiences. In our world, imperfect redness might be surface spectral reflectance property SSR21, whereas in another world it might be SSR22. Fregean contents by definition approximate Edenic contents, via the matching constraint on imperfect properties.

In Eden, perfect and imperfect properties coincide, so the two phenomenal contents of an experience always have the same truth-value. Fregean contents with their matching condition are motivated by the divergence in truth-values of the two phenomenal contents after Eden's demise. The mythical version of the fall is evocative: perceivers "eat from the trees of science and illusion." The non-mythical version is elusive: Chalmers never explains what the psychological analog is of "eating from the trees", characterizing it instead in partly mythical terms: 
It was eating from the Tree of Illusion and the Tree of Science that led us to doubt that we live in an Edenic world. Moreover, eating from these trees was an empirical process based on empirical discoveries about the world (413).

On a natural interpretation, we believe that things are (mostly) not exactly the way presentational phenomenology presents them. Chalmers suggests that we actually have those beliefs, not just that science would justify them: "Before eating from these trees, there was no special reason to doubt that our experience was perfectly veridical" (413).

Absent such beliefs, we would presumably end up believing Edenic contents when we endorse our experiences, when nothing else is stopping us from taking experiences to be veridical. Yet Chalmers holds that we end up believing only its Fregean contents, because what we believe is presumably determined by our standard of veridicality. Ordinary standards of veridicality are imperfect standards. Without the tree-eating part of the myth, there would be no motivation for positing imperfect veridicality conditions. Edenic contents with their perfect veridicality conditions would already respect intuitions about veridicality.

In holding that we don't believe Edenic contents of experience, Chalmers holds that in forming normal perceptual beliefs, we discredit the face value of our first-person perspective on the external world. Call this the Psychological Defeat Hypothesis.

The Perceptual Defeat Hypothesis seems to support Chalmers's view about what is rational to believe, if you know that presentational phenomenology is veridical. Suppose you see a pomegranate, and have the presentational phenomenology that goes with phenomenal redness. Then you learn that your experience is veridical, using the ordinary standard of veridicality. Since Chalmers identifies ordinary veridicality with imperfect veridicality, no special training should be needed to apply imperfect standards of veridicality, even if you have never engaged in the special act of holding an experience to a standard of perfect veridicality, or reflected explicitly on the distinction between standards that underlies the two-stage view.

In these circumstances, we might expect that people would believe that the pomegranate has the properties that their first-person perspective attributes to it. And intuitively, it would normally be rational for a perceiver to believe that the pomegranate has these properties. This idea is expressed by the following principle: 
(*) If S has the presentational phenomenology that is part of phenomenal redness when she sees a pomegranate, and knows that her experience is veridical by ordinary standards, then it is rational for $\mathrm{S}$ to believe that the pomegranate has the properties attributed to it by presentational phenomenology.

Principle (*) is compatible with a range of theories about perceptual justification. Perhaps the conclusion is made rational, exclusively by presentational phenomenology, together with your knowledge that the experience is veridical. Or perhaps the rational basis for this conclusion includes justification to believe that there is an external world or that in general, experiences are not misleading (Wright 2004), and that you always have such justification. Let's suppose we do always have such justification, whether we need it to form justified perceptual beliefs or not. Even given this assumption, Chalmers has to deny principle (*). Presentational phenomenology attributes perfect redness (and perfect spatial and temporal properties) to the pomegranate, whereas the ordinary standard of veridicality is imperfect veridicality. And if you learn that your pomegranate-experience is imperfectly veridical, according to Chalmers, it would be rational to conclude to that the pomegranate is imperfectly red.

Chalmers's denial of $\left(^{*}\right)$ might seem more plausible if the Psychological Defeat Hypothesis is true. That hypothesis predicts that if you told $\mathrm{S}$ that her experience was veridical, she would disregard presentational phenomenology and believe Fregean contents instead. But there are several reasons to doubt the Psychological Defeat Hypothesis.

First, ignoring presentational phenomenology is difficult, whether or not we have good reason to do so. Partially cured schizophrenics report that their auditory hallucinations (in which they hear voices speaking to them) become much easier to ignore, when they take medication that "turns down the volume". 5 The psychiatrist Brendan Maher observed that many delusional symptoms are explained in part by abnormal experiences. ${ }^{6}$ His observation derives its explanatory power

5

I first heard this reported at a Harvard Mind, Brain, and Behavior Symposium by a patient who was being interviewed by his psychiatrist Donald Goff, who said such reports are common. See also Siris et al (2012).

6

Maher (1999). 
from the assumption that people find it difficult to disbelieve their senses. The difficulty is not plausibly limited to the mentally ill. Skeptical verdicts that we shouldn't believe our senses are famously hard to live by. Or consider Franco, who talks to his cousin in a disdainful voice, even though his words express admiration for the very way his cousin inhabits the earth. If you read Franco's words on a page, you would rationally conclude that he feels strongly positive towards his cousin. But to draw this conclusion on the basis of hearing Franco speaking, you would have to disregard his disdainful tone, which is at least as salient as his words. ${ }^{7}$ The facts that disregarding it is rational for you, and that you know that it is, in no way predicts that you will actually ignore it.

In reply, Chalmers might say that the difficulty in disbelieving applies only to Fregean contents of experience, not to presentational phenomenology itself. But it's hard to see why the difficulty should apply selectively in exactly this way. What's difficult is ignoring our first-person perspective on the external world. That perspective is mirrored by Edenic contents, and is definitive of presentational phenomenology.

A different reply for Chalmers is that appearances are not uniformly difficult to discount. Some are, some aren't. Blaring television or surrounding conversations sometimes but don't always force their way to the center of attention, and their deliverances aren't always taken up into belief. But this observation doesn't help, because presentational phenomenology does not always recede from uptake in this way.

Chalmers does not specify the exact content of the "doubt that we live in an Edenic world." I've assumed that the doubt consists of beliefs that reject Edenic contents. But perhaps instead, in the non-mythical analog of Eden, what we believe is only that it is possible that things that appear perfectly $\mathrm{F}$ fail to be perfectly $\mathrm{F}$. Then tree-eating beliefs would not give us reason to reject Edenic contents.

This weaker tree-eating belief makes it more puzzling why we should end up believing Fregean contents and not Edenic contents. Standard skeptical arguments articulate possibilities in which things are not as they appear, but believing these possibilities are rarely effective at changing the

7

Perhaps even more salient, if (as seems likely) affect is processed faster than semantic information. 
beliefs we actually form. Given Chalmers's suggestion that we don't believe Edenic contents, it seems best to stick with the natural interpretation of the tree-eating beliefs, whatever their exact contents are.

\section{The rational role of presentational phenomenology}

Principle $(*)$ concerns what is rational to believe, if you know that presentational phenomenology is veridical. A related question is what is rational to believe on the basis of presentational phenomenology itself. Given that tree-eating beliefs are at odds with presentational phenomenology, what is the rational response to having both?

Everyone should agree that if the theory of refraction tells you that straight, submerged sticks look bent, while your experience of a stick being submerged tells you the stick changes shape, you should not believe your experience. In this piecemeal conflict between visual experience and vision science, science wins. In contrast, Chalmers's view posits a systematic conflict between experience and science in which science wins. Every instance of presentational phenomenology that presents spatial magnitudes, duration, or color properties - and that is just about every instance - is at odds with the science of perception (presumably a tasty fruit on the tree of science).

Where does our justification for believing Fregean contents come from, if not from presentational phenomenology and the Edenic contents that mirror it? A first option is dogmatist: experiences provide immediate, prima-facie justification for believing F-contents, by virtue of phenomenal Fregean contents. No justification for supplementary beliefs is needed. Dogmatism would apply equally to Edenic contents: experiences provide prima-facie justification for believing those, but the tree-eating beliefs defeat them. But this conclusion may not sit well with a natural account of how tree-eating beliefs are justified. If those beliefs reject Edenic contents, it is hard to see how the Edenic deliverances of experience could help justify them. Yet presumably vision science, like any science, is justified in part by the deliverances of experiences. So presumably Fregean contents do all of the justifying, even in Eden. Tree-eating beliefs are justified part by experiences, but only in virtue of Fregean phenomenal contents, not in virtue of Edenic contents. This suggests that like secondary intensions of mental states, Edenic contents never explain the rational role of experiences. If so, then they do not provide any justification for believing their contents - not even prima facie justification that gets defeated by tree-eating beliefs. 
Given Chalmers's overall picture, a more natural epistemology of perception follows the lead of traditional indirect realism, making presentational phenomenology and the Edenic contents that go with it rationally idle. On this picture, justification for believing Fregean contents of experience relies on introspective beliefs self-ascribing presentational phenomenology, together with beliefs that one is in the kind of normal conditions that would make Fregean contents true. ${ }^{8}$ In this structure for perceptual justification, it doesn't matter what form experiences take: they could be raw feels, sense-data, or contentful states. The fact that they have contents at all, Edenic or otherwise, plays no role.

Chalmers's picture is already similar traditional indirect realism in holding that the aspects of experience that define our first-person perspective - sense-data or qualia for the indirect realists, Edenic contents for Chalmers - do not by themselves identify the propositions that we typically go on to believe, or that we are typically justified in believing, upon having the experience. Traditionally, experiences fail to identify these propositions, because they have an entirely different subject-matter from perceptual belief: mental objects or raw feels, rather than externalworld objects and their properties. In Chalmers's picture, Edenic contents have the external world as their subject-matter. But the similarity remains, since Edenic contents (via the matching condition) only indirectly determine the contents we normally believe in response to the experience.

The indirect semantic connection Chalmers finds between presentational phenomenology and justified perceptual belief takes some dramatic forms. He argues that we have justified beliefs in the Matrix scenario. Your body - or at least, the body that houses your brain might be forever strapped to a chair, but that fact alone does not rule out that your experience as of walking in Tucson is veridical. How could you be walking in Tucson, if your body is strapped to a chair? Chalmers argues that your experience can be imperfectly veridical, even if its supervenience base happens to be inside the head of a body that is strapped to a chair. ${ }^{9}$ Similar consequences pertain

\section{8}

I'm encouraged in this suggestion by the fact that Chalmers (2012) expresses sympathy with it in a more recent discussion of structuralist responses to skepticism.

9

More exactly, your brain* is in the body walking in Tucson, but the brain housing the supervenience base of your experience is in the body strapped to a chair. 
to our spatial experience, which Chalmers says tolerates great discrepancies between the spatial properties that figure most immediately in our experience, such as the Edenic size and shape of

one's hand, and the corresponding imperfect properties. These consequences rely on the idea that the deliverances of presentational phenomenology do not directly determine what we believe on the basis of experience.

Some theorists who oppose indirect realism would criticize Chalmers's epistemology of perceptual belief, on the grounds that it saps away rational force that properly belongs to presentational phenomenology. My criticism is instead that it saps away its psychological force in perceptual belief formation. If the phenomenal contents that mirror phenomenal character are divorced from those that track assessments of veridicality, then phenomenal character is neutralized as a chief determinant of what we normally believe in response to our experience. From there, it may be natural enough for phenomenal character to be rationally idle, as well. But the implausibility starts earlier, with the division between how things most immediately seem to us in perception, and what we go on to believe.

\section{References}

D. Chalmers 2012. Constructing the World. Oxford University Press

B. Maher. 1999 "Anomalous experience in everyday life: Its significance for psychopathology," The Monist, 82: 547-70.

A. Pautz 2011. “Can Disjunctivists Explain Our Access to the External World?” Philosophical Issues 21: 384-433.

S. Siegel 2010. The Contents of Visual Experience. Oxford University Press.

S. Siris and F. Acosta. "Qualitative content of auditory hallucinations and suicidal behavior in schizophrenia" Schizophrenia Research 134 (2012) 298-299.

A. D. Smith 2002 The Problem of Perception. Cambridge: Harvard University Press.

R. Stalnaker 2008. Our Knowledge of the Internal World. Oxford University Press.

C. Wright 2004. "Warrant for nothing (and foundations for free)?” Aristotelian Society

Supplementary Volume 78 (1): 167-212. 